\title{
Why do we need harmonization in thoracic surgery: a view from above by the European Union of Medical Specialists
}

\author{
Toni Lerut ${ }^{1,2}$, Dirk Van Raemdonck ${ }^{1,2}$, Gilbert Massard ${ }^{3,4}$ \\ ${ }^{1}$ Department of Chronic Diseases, Metabolism, and Aging, KU Leuven University, Leuven, Belgium; ${ }^{2}$ Department of Thoracic Surgery, University \\ Hospitals Leuven, Leuven, Belgium; ${ }^{3}$ Department of Thoracic Surgery, Hôpitaux Universitaires de Strasbourg, Strasbourg, France; ${ }^{4}$ Faculté de \\ Médecine, Université de Strasbourg, Strasbourg, France \\ Contributions: (I) Conception and design: T Lerut; (II) Administrative support: None; (III) Provision of study materials or patients: All authors; (IV) \\ Collection and assembly of data: All authors; (V) Data analysis and interpretation: All authors; (VI) Manuscript writing: All authors; (VII) Final \\ approval of manuscript: All authors. \\ Correspondence to: Toni Lerut, MD, PhD. Department of Thoracic Surgery, University Hospitals Leuveny, Leuven, Belgium. \\ Email: toni.lerut@kuleuven.be.
}

\begin{abstract}
Founded in 1958 the UEMS (Union Européenne des Médecins Spécialistes-European Union of Medical Specialists) has become the largest European Medical organization representing over 1.5 million specialists of 43 Specialties in 39 countries. The primary goal of UEMS is to defend the interests of Specialists in the broadest sense of the word. This includes promoting the highest quality of care, the highest standards of training, continuous professional development (CPD) and continuous medical education (CME). For the latter the European Accreditation Council for Continuous Medical Education (EACCME) is one of the main assets of UEMS. The UEMS Section of Thoracic Surgery was created in 2013 and has substantially contributed to the improvement of the identity of Thoracic Surgery as a specialty throughout Europe. Its main activities are focusing on harmonization of training and organization of the format of the UEMS Board in Thoracic Surgery as well as further molding of the specialty via an intense collaboration with all involved stakeholders over the specialty boundaries.
\end{abstract}

Keywords: Thoracic surgery; training; accreditation; harmonization; continuous professional development (CPD)

Submitted Oct 06, 2018. Accepted for publication Jan 14, 2019.

doi: $10.21037 /$ jtd.2019.01.49

View this article at: http://dx.doi.org/10.21037/jtd.2019.01.49

\section{What is European Union of Medical Specialists (UEMS)?}

The treaty of Rome creating the European Economic Community was signed on the $25^{\text {th }}$ of March 1957 by Belgium, France, Italy, Luxemburg, The Netherlands, and West Germany. Very soon thereafter representatives delegated by the professional organizations representing medical specialists in the six-member countries of the very new European Community (EEC) convened in Brussels. On July 1958 they created the Union Européenne des Médecins Spécialistes-European Union of Medical Specialists (UEMS) (1). The first Statutes emphasized the role of UEMS in promoting the highest quality of care and training of medical specialists in Europe for the benefit of the health of all European citizens.

Today the UEMS is made up of 40 National Member Associations, which altogether compose the UEMS Council, which is the organization's General Assembly. There are three types of National Member Associations within the UEMS: Full Member Association (Member States of the European Union \& Member States of the European Economic Area), Associate Member Association (Member States of the Council of Europe) and Observer Member Association (other countries).

In 1962, the UEMS created Specialist Sections to promote and defend the interest of the different Specialties at the European level. Currently, 45 Specialist Sections, 
15 Multidisciplinary Joint Committees and over 20 Divisions are active in this regard. UEMS represents over 1.5 million medical specialists in all the different specialties (2). UEMS also has strong links and relations with European Institutions (Commission and Parliament), and other independent European Medical Scientific Societies. By its statutes, UEMS promotes the standards for high quality healthcare practice that are transmitted to the National Medical Associations and to the Authorities and Institutions of the EU stimulating and encouraging them to implement its recommendations.

The expertise of the UEMS is based on three pillars:

(I) continuing medical education and professional development (CME-CPD);

(II) post graduate medical training (PGT);

(III) quality assurance (QA).

In Europe each Member State is responsible to organize the training of medical doctors. However, the UEMS committed itself to contribute to the improvement of medical training at the European level through the development of European Standards in the different medical disciplines.

The UEMS main actions in this regard consists in:

(I) setting the basis for European standards in medical training;

(II) advocating for competence-based training and assessment;

(III) developing a mechanism of evaluation of medical specialists' competence at the European level;

(IV) organizing European examinations;

(V) appraisal and accreditation of training centers.

It is to the different Sections to implement these actions and to organize the exams through their Boards. The Council for European Specialists Medical Assessment (CESMA) is an advisory body of the UEMS created in 2007 with an aim to provide recommendation and advice on the organization of European examinations for medical specialists at the European level.

As progress in Medicine becomes faster and faster, the necessity to up-date one's knowledge is becoming even greater. Whereas many individual Member States have created obligatory systems of CME-CPD, the EU has not demanded any such mandatory system of CME-CPD at European level. The UEMS therefore has established the European Accreditation Council for CME (EACCME) in order to provide appropriate credits (hours) for CMECPD activities to individual medical specialists throughout Europe but without interfering with the national existing national organizations in this respect.

The ultimate goal is the development of new, harmonized models for the training of the next generation of medical specialists, and of high standards of clinical practice, hence improved care for patients throughout Europe.

However, since in Europe, each souvereign member state is responsible to organize the training and postgraduate formation of medical doctors and quality assurance the obvious question is:

(I) Do we really need harmonization of training, continuing medical education and continuing professional development?

The answer is obviously yes for several reasons:

First and foremost, important is the EU Directive 2004/38/EC also called the free movement directive. This directive applies to health care professionals and patients as well. That means that the European Member State health care systems are inter-dependent. The more recent addition of several new member states is in this respect a major challenge as in many young democracies, assessments of training, competence and professional development may have different back grounds and quality levels. European regulations stipulate automatic reciprocal recognition of specialty diplomas: however, if diplomas are considered equal, they should certify equal training curricula, and be obtained by equal modalities of assessment of competence

This challenge becomes even bigger as a consequence of EU Healthcare Directive 2011/24/ EU on the patients' rights in cross-border healthcare. According to this directive the freedom to receive health services throughout the European Union must be accompanied by guarantees of quality and security. In order to make an informed choice, patients must be able to access all the information they require on the conditions under which they will receive healthcare in another EU Member State and the conditions under which they will be reimbursed once they return home.

Quality of outcomes, transparency, accountability are the key words justifying the need for harmonization of training requirements, continuous medical education (CME) and continuous professional development (CPD) centers in an ever faster changing and more demanding society.

Criteria of selection for training of specialists, 
post specialization training, development of fit for purpose training centers, training of the trainers, state of the art training, supervision, monitoring and professional skills evaluation, accreditation, reaccreditation are only a few commonly used terms in the health care vocabulary of today.

Needless to say, that these aspects of healthcare go hand in hand with financial challenges, challenges of workforce planning. Not to forget the changing landscape of health problems, new emerging technologies and the different needs and demands by patients: the users of healthcare services.

Migration of inhabitants of third world countries or war zones has been dominating the political scenery during the last decade. These immigration waves will bring in diseases that have become rare in our western societies e.g., tbc, Ecchinococcus, malaria, fungal diseases, etc. and thus requiring trainees to become familiarized with.

However, the EU Directive 2003/88/EC regulating the organization of working time and the working hours restrictions have had a dramatic impact on both elective time and time on call of doctors reducing exposure to clinical work and training, especially for trainees in surgery. In many countries directors of training program are still struggling to find an adequate answer for this issue.

Whilst on the other hand the enormous boom of new emerging surgical technologies and innovative medications are revolutionizing both diagnostic as well as therapeutic armamentarium. The result is a dramatic increase of the complexity of health care and a further need for sub- or super specialization. In the USA there are now 158 specialties and subspecialties.

Super fellowships are prolonging the training period. In the USA the mean length of training in (cardio-) thoracic surgery is 8 years. In Norway 9.47 years in the period 2004-2013 (3).

Along with the aging and thus prolonged life time with more comorbidities there is also a problem of aging of the specialist population. According to the Association of American Medical Colleges he mean age of (Cardio) Thoracic surgeons in the USA in 2015 was 52.4 years and $57 \%$ of them being 55 years or more (4)! In Canada $34 \%$ of thoracic surgeons are over 50 years but $20 \%$ plans to retire before age 60 and another
$35 \%$ before 65 (5).

In 2009 , about $30 \%$ of all doctors in the EU were over 55 years of age. By 2020 estimated shortage of health care workers is 1 million, out of whom 230,000 physicians.

A shortage that will have to face the dramatically increasing demand for healthcare with Europe's aging population. The number of elderly persons aged 65 and over is projected to almost double over the next 30 years. The increasing numbers of elderly people with multiple chronic conditions will require new treatments and new care delivery models (6).

Needless to say, that assessing the needs workforce also for Thoracic Surgery is becoming of critical importance.

(II) How to address all the challenges?

Within the organograms of UEMS Sections, the Boards are the working parties that reflect on:

(i) training requirements (clinical, academic, professional);

(ii) standards of clinical care;

(iii) accreditation of trainers;

(iv) appraisal and accreditation of training centers.

The content and the format of the exams are based on the existing experience across Europe and beyond and consultation of already existing national boards in order to generate innovative ideas. The goal is not to work on the basis of the lowest common denominator but to aim for a consensus on the highest possible standards.

Preparatory courses for the future applicants are organized in close collaboration with the European learning societies.

However, the UEMS Board exams do not replace the National exit criteria required to obtain the Certificate of Completion of Specialist Training (CCST).

Since the UEMS is not an official European Commission related body, the diploma obtained after successful national exam is to be considered as an extra quality label. A label that in recent years is more and more sought after when a young specialist is applying for a job.

Nevertheless, for some specialties or in some countries the UEMS exam or part of it is accepted an official part of the exit procedure to obtain the 
CCST e.g., anesthesiology, urology, pulmonary medicine.... The UEMS seeks to increase the probability of more countries using the UEMS Board exams to become part of their national exit procedure.

Within this context, the Council of European Specialists Medical Assessments (CESMA) has been created to harmonize the way the exams are organized by the different UEMS Boards. Its activities consist of an appraisal of such items as curriculum, format, content of the exams, fairness and professionalism of the examiners, marking process, decision making process for pass/fail, quality control mechanisms (e.g., external examiners), offer feedback, training the examiners, etc.

Future efforts will focus on accreditation of training centers at a European level including e.g., on site visits, accreditation of clinical skills centers etc.

In short, the common denominator and related challenge is that, if the medical profession-in case UEMS, is not taking initiative, others-in case administrators and politicians, will interfere or take over.

\section{The UEMS Section \& Board of Thoracic Surgery (7)}

In October 1996, EACTS (European Association for Cardio-Thoracic Surgery), ESTS (European Society of Thoracic Surgeons) and ESCVS (European Society of Cardiovascular Surgery) decided to establish a board, called The European Board of Thoracic and Cardiovascular Surgeons (EBTCS). The primary goal of EBTCS was to create a common high standard for the quality of thoracic and cardiovascular surgery across Europe. This was also seen as a vehicle for mutual recognition between European Countries.

As of 1996 board exams were organized issuing a certificate of Fellow of the European Board of Thoracic and Cardiovascular Surgeons (FEBTCS) for thoracic surgeons who passed the exam of Thoracic Surgery and for Cardiac surgeons who passed the exam of Cardiac surgery.

Over the following years the need was felt to integrate within a broader European organization i.e., the UEMS.

In 2004 the UEMS Section of Cardio-Thoracic Surgery was established consisting of a Division of Thoracic Surgery and a Division of Cardiac Surgery.
However, it was also decided by the UEMS executive to create a Division of Thoracic Surgery within the Section of Surgery.

The UEMS European Board of Thoracic and Cardiovascular Surgery continued its activities as before. But for Thoracic Surgery the Board existed now as a Unified Board for Thoracic Surgery representing both the Division of Thoracic Surgery of the Sections of Cardio Thoracic Surgery and the Section of Surgery, respectively.

By the turn of the millennium it had become clear that Thoracic Surgery was experiencing a true revival. The introduction of video-assisted thoracoscopic surgery (VATS) fueled the need for much more profiled thoracic surgeons. With the increasing waves of migration an increase in the role of thoracic surgery was seen for surgical treatment of infectious diseases. Also, thoracic interventions in immunedepressed patients were on the rise. Lung transplantation was expanding as was lung volume reduction surgery. Oncologic developments resulted in a need for profiled multimodality programs in thoracic oncology. Pulmonary metastasectomy became increasingly accepted especially when performed through VATS. Pleurectomy or extrapleural pneumonectomy became an accepted indication in selected patients with mesothelioma, etc.

As a result of this ever-growing identity of Thoracic Surgery reflected by its existence a mono specialty in over one third of the European Union member states, a UEMS Section of Thoracic Surgery was created in 2013 and both Divisions of Thoracic surgery within the Section of CardioThoracic Surgery and the Section of Surgery being winded up. Within the UEMS Section of Thoracic Surgery a Board of Thoracic Surgery (EBTS) has been established as of 2013 issuing a certificate of fellow of the European Board of Thoracic Surgery (FEBTS). The Board exams are organized in collaboration with the two involved Scientific Societies ESTS and EACTS.

However General Thoracic Surgery was, and still is, one of the smaller specialty groups in medicine. It has developed differently throughout Europe in a number of countries integrated in cardiothoracic surgery or in general surgery. Its variable position throughout Europe was seen as major obstacles for surgeons who wanted to dedicate themselves to thoracic surgery as well as for patients seeking optimal treatment. The result being that one center may be treating no more than 10 patients per year another over 1,000 patients each year. In many centers thoracic surgery patients were postoperatively scattered over different wards while in other institutions all thoracic surgery patients 
were hospitalized in thoracic surgery wards manned by a specifically trained nursing staff and other paramedical personnel. The obvious consequence being a considerable variation in levels of experience.

Therefore, the leadership of ESTS and EACTS in 2001 jointly published a document on Structure of General Thoracic Surgery in Europe intended as guidance to national governments and regional authorities (8). This publication had clearly a substantial impact greatly endorsing the ongoing molding of Thoracic Surgery as a well-identified subspecialty.

This landmark publication later was updated in 2014 to "...represent the first step of a process of revision of the modern thoracic surgeons' curricula, which need to be qualitatively rethought in the setting of the qualification process" (9).

The diversity of the organization of the training and practice of Thoracic Surgery has been well illustrated by a survey amongst delegates of the then still existing Division of Thoracic Surgery within the Section of Cardio-Thoracic surgery in 2013 (10).

Diversity was observed in length of training (5-10 years), in exposure to pure thoracic surgery during the training period ( $2-5$ years), in the authority issuing the CCST (professional medical body, university, ministry of health, ministry of education...), in the number of required operations as 1 st surgeon during training (none-1,000 interventions).

But the survey also revealed that thoracic surgery was a mono-specialty in 13-member states of the EU. According to the statutes this number sufficed to create a Section of Thoracic Surgery and the subsequent application was approved by the UEMS Council in 2013.

In the following years further molding of thoracic surgery has occurred and also in countries where thoracic surgery remains integrated in a cardio-thoracic specialty separate tracks for thoracic, adult cardiac and congenital cardiac surgery have become reality in most countries.

In the UK for instance trainees have to declare after the common trunk their interest in either thoracic or cardiac surgery for the last part of their training and they will be allowed to only practice the track they'd chosen. As to the consultants it is clear that in the long-term mixed practice surgeons will be replaced by consultants with job plans consisting entirely of either thoracic or cardiac surgery. It is likely that those mixed practice surgeons with a 50:50 division of their work are the ones who will move to full time thoracic surgery, whereas those with a small thoracic practice will become full-time cardiac surgeons (11).

The global mission of the UEMS Section of Thoracic Surgery is as follows (7):

(I) the study, promotion and harmonization of the highest level of training, medical practice of thoracic surgery and related health care within the member states of the European Union;

(II) the study and promotion of free movement of thoracic surgeons within member states within the $\mathrm{EU}$

(III) in compliance with UEMS Statutes the representation to EU authorities and any other authority and/or organization dealing with questions directly or indirectly concerning thoracic surgery;

(IV) the defense of the professional interests of European thoracic surgeons.

The UEMS Section of Thoracic surgery realizes its global mission through the achievement of the following aims:

(I) to achieve the highest possible level in training of specialists and to promote harmonization of training and its regulations within the EU member states;

(II) to promote life-long learning after completion of specialist training by complying to the appropriate national and UEMS criteria in this respect, in particular concerning $\mathrm{CME}$ and $\mathrm{CPD}$;

(III) to ensure that practice of thoracic surgery is achieved within EU regulations, and to follow both harmonization and development of regulations at the European level;

(IV) to promote free mobility of thoracic surgeons throughout European member states;

(V) to promote standardization of the structure of thoracic units within the EU member states;

(VI) to promote quality of care by outcome measurements; to stimulate development of European databases;

(VII) to promote equal access to care in thoracic surgery in Europe and to defend European mobility of patients;

(VIII) to develop advocacy of thoracic surgery within the EU member states in close collaboration with the UEMS management council;

(IX) to promote thoracic surgery related research;

(X) to promote good corporate governance principles amongst leadership in thoracic surgery within the EU member states.

The Section of Thoracic Surgery therefore has created, 
in line with the UEMS statutes, a working group which is UEMS Board of Thoracic Surgery in order to:

(I) recommend the standards required for the training of their specialists, including definition of syllabus and curriculum;

(II) make proposals for monitoring quality and content of training and maintenance of standards;

(III) set up criteria which training centers should fulfill and to promote accreditation of training units;

(IV) facilitate the exchange of specialist trainees between training centres of the EU member states to ensure a better harmonization and quality of training;

(V) organize a board examination to certify European thoracic surgeons.

\section{Crossing the borders: collaboration}

In view of the existing variations in the organization of training and evaluation of learning outcomes and the presumed related variations in quality, a need was felt to produce a training syllabus containing the fundamentals that a trainee should master.

An initiative was taken as a collaborative effort between the European learning societies ESTS and EACTS on one hand and the ERS HERMES (Harmonized Education in Respiratory Medicine for European Specialists) task force. Indeed, this task force had a long and strong experience in curriculum designing methodology. Given the obvious importance of such a harmonized syllabus the UEMS Section of Thoracic Surgery became a stakeholder as well in this initiative. The details of it will be further explained in a chapter of this issue of JTD specifically dealing with this topic.

The syllabus has been recently published in the European Fournal of Cardio Thoracic Surgery (12) and will be further dispersed amongst National Societies of Thoracic Surgery. It serves as a guideline describing the content of training and is designated to trainees, directors of training programs, and specialty boards. In addition, it will be used as well to further fine tune the courses organized by the learning societies to help trainees to prepare for the exams by the UEMS Board of Thoracic Surgery.

The next steps are to work out the curriculum which follows the lines of the syllabus and describes in detail the when and how for each module and item: at which time-point it should be learned, which learning resources should be employed, and which tools should be used to assess learning outcomes i.e., the specifics on knowledge of diseases and operative skills.

Over the years many Sections have adapted and/ or refined their exam format in part influenced by the recommendations from CESMA. Many sections are now utilizing for part 1 of the exam multiple choice questions (MCQ's) followed by part 2 under form of a viva.

Setting up MCQ's is a difficult, time consuming and costly process requiring collaboration of a substantial number of international question writers. The questions need to be carefully scrutinized requiring support from educational scientists' input.

The European Board of Cardio Thoracic Surgery is an independent organization mandated by EACTS to organize exams in cardiothoracic surgery. With the logistic support and longstanding expertise of the Royal College of Surgeons of Edinburgh, a working party consisting of more than 20 international question writers has produced written paper MCQ's in the generality of cardiothoracic surgery. This resulted in a pool of 180 single-best answer questions validated with the help of an examination assessment software provided by a professional (Ripley Systems) company and using the Angoff method for cutoff point (pass mark) by a group of more than 10+ established experts/examiners.

Contacts have been made to investigate a possible collaboration amongst the different stakeholders involved in the organization of the UEMS Board of Thoracic Surgery with the aim to establish a similar high quality MCQ database to be used in the future for step 1 of the EBTS exam.

Some specific areas of pathology are dealt with in only few centers e.g., lung transplantation and are also overlapping with other specialties e.g., esophageal diseases.

Lung transplantation is performed in few specialized units in centers that are also dealing with other types of solid organ transplantation.

In the UEMS Section of Surgery, a Division of Transplantation has been created some years ago and which appeared to be very successful.

Within the UEMS Section of Thoracic Surgery an initiative has been launched to create Division of Lung Transplantation in collaboration with an ESTS working group on lung transplantation. Starting with the modules Chest organ retrieval and Lung transplantation of the HERMES task force syllabus, the curriculum for Lung transplantation will be further completed. The next step will be to link up with the UEMS Section of Cardiothoracic Surgery and work out a module for Heart Transplantation and finally integrate these modules in to the broader basic knowledge modules established by the UEMS Division of 
Transplantation within the UEMS Section of Surgery.

Surgical treatment of esophageal diseases is also a complex field dealt with by specialized units of Thoracic Surgery. But esophageal surgery overlaps with visceral surgery centers with specialized upper GI surgery units.

Very recently a Division of Oesophagogastric surgery was created within the UEMS Section of Surgery. After mutual consultation between representatives of the Division of Oesophagogastric surgery and the Section of Thoracic Surgery it was felt that there is a common interest to work together on a common curriculum for trainees who want to become dedicated esophageal surgeons. Indeed, surgery of the esophagus requires familiarity with anatomy and physiopathology of both the thoracic and abdominal cavity. Consequently, a Division of Upper GI was formed within the UEMS Section of Thoracic Surgery. Starting from the module Esophagus of the HERMES task force syllabus as well as catalogue from the Oesophagogastric surgery division, the working party consisting of delegates of both divisions is working on the outline of the curriculum eventually culminating in one common UEMS Division of upper GI/oesophagogastric surgery.

Surgical treatment of cancer of the lung as well as of the esophagus today is part of a complex multimodality approach. Each patient therefore has to be discussed within a multidisciplinary tumor board offering an optimal therapeutic plan for each individual patient. Indeed, there is evidence that a multidisciplinary approach to any cancer improves quality of life and survival (13). To optimize the collaboration between the involved specialties the idea has grown to create a task force group under the form of a UEMS Multidisciplinary Joint Committee (MJC) involving the UEMS Sections of Thoracic Surgery, Pulmonary Medicine, Medical Oncology, and Radiation Oncology \& Radiotherapy planning to set up a European Certification in Thoracic Oncology accredited by UEMS.

The main goal is to issue recognition of competence to lead a multidisciplinary tumor board, in addition. Considerable preparative work in terms of curriculum development has been made by a HERMES task force gathering experts from the European Respiratory Society (ERS), the European Society of Thoracic Surgeons (ESTS), the European Society of Medical Oncology (ESMO), and the European Society of Thoracic Radiation Oncology (ESTRO) serving as the basis for thoracic oncology training in Europe $(14,15)$.

This UEMS MJC accredited subspecialty certificate would add to the already validated specialty diploma in any of the involved specialties. This certification should be easily accessible to thoracic surgeons, because most items can be addressed during the training period. This labeling would represent an added value for colleagues searching for European mobility, and of course for liability issues.

\section{Conclusions}

Over time the UEMS has evolved in to the biggest organization for Medical Specialists. It therefore represents a unified voice in the international representation of Medical Specialists. UEMS pursues international excellence in key areas of relevance to the medical profession through effective interaction with and support of the National Medical Associations and Medical Specialties represented by individual Sections as well as with their related European Scientific Societies. As such UEMS plays a key role in addressing interdisciplinary issues in emerging areas of medical specialties. UEMS has set the basis for a solid system for accreditation of live educational meetings. UEMS has a strong influence in the development of harmonized models of training of the future medical specialists as well as addressing interdisciplinary issues in emerging areas of medical specialties.

The recently created UEMS Section of Thoracic Surgery has undoubtedly been instrumental in improving the identity of this Specialty through a variety of initiatives. Its actual primary goals are harmonizing the training curriculum, the organization of the format of the UEMS Board of Thoracic Surgery and further molding of the specialty via an intense collaboration with all involved stakeholders over the specialty boundaries.

\section{Acknowledgments}

The authors thank all the Delegates of the UEMS Section of Thoracic Surgery and Prof R. Krajewski President of UEMS and Prof V. Papalois, Secretary General of UEMS for their invaluable help.

Funding: None

\section{Footnote}

Provenance and Peer Review: This article was commissioned by the editorial office, Fournal of Thoracic Disease for the series "Training in Pulmonary Medicine and Surgery". The article has undergone external peer review.

Conflicts of Interest: All authors have completed the ICMJE 
uniform disclosure form (available at http://dx.doi. org/10.21037/jtd.2019.01.49). The series "Training in Pulmonary Medicine and Surgery" was commissioned by the editorial office without any funding or sponsorship. GM served as the unpaid Guest Editor of the series. The authors have no other conflicts of interest to declare.

Ethical Statement: The authors are accountable for all aspects of the work in ensuring that questions related to the accuracy or integrity of any part of the work are appropriately investigated and resolved.

Open Access Statement: This is an Open Access article distributed in accordance with the Creative Commons Attribution-NonCommercial-NoDerivs 4.0 International License (CC BY-NC-ND 4.0), which permits the noncommercial replication and distribution of the article with the strict proviso that no changes or edits are made and the original work is properly cited (including links to both the formal publication through the relevant DOI and the license). See: https://creativecommons.org/licenses/by-nc-nd/4.0/.

\section{References}

1. Union Européenne des Médecins Specialistes/European Union of Medical Specialists. Available online: http://www. uems.eu

2. Papalois V. Training, education, accreditation and professional development in surgery in Europe: the perspective of the European Union of Medical Specialist (UEMS). Cir Esp 2017;95:131-4.

3. Glomsaker TB, Søreide K. Surgical training and working time restriction. Br J Surg 2009;96:329-30.

4. AAMC. 2016 Physician Specialty Data Report. Available online: https://www.aamc.org/data/workforce/ reports/457712/2016-specialty-databook

5. Grondin SC, Schieman C, Kelly E, et al. A look at the

Cite this article as: Lerut T, Van Raemdonck D, Massard G. Why do we need harmonization in thoracic surgery: a view from above by the European Union of Medical Specialists. J Thorac Dis 2021;13(3):2021-2028. doi: 10.21037/jtd.2019.01.49 thoracic surgery workforce in Canada: how demographics and scope of practice may impact future workforce needs. Can J Surg 2013;56:E75-81.

6. European commission staff working document on an Action Plan for the EU Health Workforce 2012. Available online: https://eur-lex.europa.eu/legal-content/EN/TXT/ PDF/?uri=CELEX:52012SC0011\&from=BG

7. European Section of Thoracic Surgery. Available online: https://uemsthorax.eu/

8. Klepetko W, Aberg TH, Lerut AE, et al. Structure of general thoracic surgery in Europe. Eur J Cardiothorac Surg 2001;20:663-8.

9. Brunelli A, Falcoz PE, D'Amico T, et al. European guidelines on structure and qualification of general thoracic surgery. Eur J Cardiothorac Surg 2014;45:779-86.

10. Depypere LP, Lerut AE. Thoracic surgical training in Europe: what has changed recently? Ann Transl Med 2016;4:89.

11. NHS England. Schedule 2 - The Services. Service specifications. Available online: https://www.england.nhs. uk/wp-content/uploads/2017/07/thoracic-surgery-servicespecification.pdf

12. Melfi FM, Chella A, Menconi GF, et al. Intraoperative radioguided sentinel lymph node biopsy in non-small cell lung cancer. Eur J Cardiothorac Surg 2003;23:214-20.

13. Stephens MR, Lewis WG, Brewster AE, et al. Multidisciplinary team management is associated with improved outcomes after surgery for esophageal cancer. Dis Esophagus 2006;19:164-71.

14. Gamarra F, Boffetta P, De Ruysscher D, et al. Thoracic Oncology HERMES syllabus: setting the basis for thoracic oncology training in Europe. Eur Respir J 2013;42:568-71.

15. Gamarra F, Noël JL, Brunelli A, et al. Thoracic oncology HERMES: European curriculum recommendations for training in thoracic oncology. Breathe (Sheff) 2016;12:249-55. 